\title{
Arsenic trioxide inhibits Hedgehog, Notch and stem cell properties in glioblastoma neurospheres
}

\author{
Dacheng Ding ${ }^{1+}$, Kah Suan $\operatorname{Lim}^{2+}$ and Charles G Eberhart ${ }^{2,3,4^{*}}$
}

\begin{abstract}
Background: Notch and Hedgehog signaling have been implicated in the pathogenesis and stem-like characteristics of glioblastomas, and inhibitors of the pathways have been suggested as new therapies for these aggressive tumors. It has also been reported that targeting both pathways simultaneously can be advantageous in treating glioblastoma neurospheres, but this is difficult to achieve in vivo using multiple agents. Since arsenic trioxide has been shown to inhibit both Notch and Hedgehog in some solid tumors, we examined its effects on these pathways and on stem cell phenotype in glioblastoma.

Results: We found that arsenic trioxide suppresses proliferation and promotes apoptosis in three stem-like glioblastoma neurospheres lines, while inhibiting Notch and Hedgehog target genes. Importantly, arsenic trioxide markedly reduced clonogenic capacity of the tumor neurospheres, and the stem-like CD133-positive fraction was also diminished along with expression of the stem cell markers SOX2 and CD133.
\end{abstract}

Conclusions: Our results suggest that arsenic trioxide may be effective in targeting stem-like glioblastoma cells in patients by inhibiting Notch and Hedgehog activity.

\section{Introduction}

Glioblastoma (GBM) are the most common primary adult brain malignancy, and despite some advances in therapeutic options survival remains dismal. One reason suggested for the deadliness of this disease is the presence of treatment-resistant stem-like cancer cells [1-6]. While conventional therapies are thought to target much of the tumor, it is believed that stem-like neoplastic cells survive and go on to regenerate the lesion. We therefore need new therapies targeting these cancer stem cells (CSC) in glioma.

Notch and Hedgehog signaling have been implicated in the survival of CSC in GBM by our group and others, and single agent therapies targeting either pathway have yielded promising results [7-17]. However, single therapies often allow resistance to develop in tumor cells, suggesting that several pathways will need to be targeted simultaneously if we are to eradicate GBM in patients.

\footnotetext{
* Correspondence: ceberha@jhmi.edu

${ }^{\dagger}$ Equal contributors

${ }^{2}$ Departments of Pathology, Johns Hopkins University School of Medicine,

Baltimore, MD 21287, USA

${ }^{3}$ Oncology, Johns Hopkins University School of Medicine, Baltimore, MD 21287, USA

Full list of author information is available at the end of the article
}

Our group recently identified one mechanism of cellular resistance to Notch pathway inhibition in GBM: direct upregulation of the Hedgehog pathway through a novel cross talk mechanism. This involved constitutive suppression of Hedgehog activity by direct binding of the Notch mediator HES1 to the GLI promoter [18]. While dual agent therapy with separate compounds targeting both Notch and Hedgehog was able to overcome this problematic therapeutic resistance, toxicity and other issues limit the in vivo use of the specific agents tested in our prior study. We have therefore now investigated the potential of a single compound, arsenic trioxide (ATO), to target both Notch and Hedgehog signaling in stem-like glioma cells.

Arsenic trioxide was first used in the treatment of acute promyelocytic leukemia (APL) in China, where one of the potential mechanisms of action involved induction of differentiation of leukemic cells $[19,20]$. ATO has since been FDA approved for treatment of APL patients for which ATRA failed to work [21]. The effects of ATO were subsequently examined in other tumor types, including multiple myeloma, glioma, neuroblastoma, esophageal carcinoma and prostate cancer, and it has been found to be efficacious in many of these as well [22-27]. 
The mechanism of action of ATO is not entirely clear, but in many tumors it is thought to function via regulation of various developmental pathways important in cancer. In APL for example, ATO inhibits the oncogenic fusion protein promyelocytic leukemia-retinoic acid receptor $\alpha$ (PML-RAR) [28]. In other tumors such as basal cell carcinoma, ATO is believed to exert its effects by inhibiting the Hedgehog signaling pathway [29]. Finally, in one report using glioma cells grown adherently, ATO was shown to target Notch signaling [30].

A number of studies have looked at the anti-growth effects of ATO in gliomas, however all but one were done using adherent glioma lines grown in high serum $[27,30-40]$. It has been suggested that glioma cells grown under these conditions are poor models in which to address CSC related issues [41]. We therefore used several serum-free glioblastoma neurosphere cultures to examine the effects of ATO on the growth and survival of stem-like tumors cells, as well as its effects on key developmental pathways such as Notch and Hedgehog. We found that ATO inhibits both of these pathways, along with growth, clonogenicity and stem-cell characteristics in the GBM neurospheres.

\section{Material and methods}

\section{Cell culture condition and drug preparation}

HSR-GBM1, 040622 and 040821 neurosphere lines were kind gifts from Dr. Angelo Vescovi. They include two temozolomide resistant neurosphere cultures (HSRGBM1 and 040622) and one temozolomide sensitive one (040821) [42]. None are mutated at the IDH1 locus, and HSR-GBM1 and 040622 lack alterations in p53, while 040821 cells have a mutation in p53 exon 7 resulting in substitution of serine for proline in amino acid 278. All are completely methylated at the MGMT locus. Prior studies have shown that all three lines are sensitive to pharmacological Notch blockade $[7,18,42]$, while Hedgehog inhibition has been shown to inhibit growth and clonogenicity of HSR-GBM1 and 040622 (HSR-GBM2) cells [8,18]. GBM neurospheres were maintained in Neurocult Complete Medium supplemented with human epidermal growth factor and human fibroblast growth factor (Peprotech, Rocky Hill, NJ). Arsenic Trioxide (ATO) powder (Sigma, St Louis, Mo-Aldrich) was dissolved in $1 \mathrm{mM}$ sodium hydroxide. Cell number and viability were assessed using the hemocytometer and trypan blue.

\section{Determination of cell growth}

We performed MTS assays to determine growth in viable cell mass. Cells were seeded into 96-well plates at a density of 5000 per well in $100 \mu \mathrm{l}$ of medium. Cells were then treated with concentrations of arsenic trioxide (ATO) ranging from $0 \mu \mathrm{M}$ to $5 \mu \mathrm{M}$ and incubated in $5 \% \mathrm{CO} 2$ at $37^{\circ} \mathrm{C}$. For the MTS readings, $20 \mu \mathrm{l}$ of MTS solution was added to each well at 24, 48 and 72 hours post plating and incubated for 1 hour. After that optical density was measured by spectrophotometer. The experiments were repeated at least three times for each cell line.

\section{Cell proliferation assay}

BrdU assay was performed to determine proliferation. Cells were treated with concentrations of ATO ranging from $0 \mu \mathrm{M}$ to $5 \mu \mathrm{M}$ for 72 hours, and then cytospun onto slides. They were then fixed with $4 \%$ formaldehyde in PBS for 15 minutes, and permeabilized with $0.1 \%$ Triton/PBST for 15 minutes. Cellular proteins were then denatured with $2 \mathrm{~N} \mathrm{HCL}$, washed with PBST (PBS Tween-20), blocked with 5\%NGS/PBST for 15 minutes and then incubated in primary antibody against BrdU (Sigma, B2531). Anti-BrdU antibody was used per the manufacturer's instruction at 1:500 dilution. After washing 3 times with PBST, cells were incubated for 45 minutes in the dark with the appropriate cy-3 conjugated secondary antibody. Cells were then counterstained with 4',6-diamidino-2-phenylindole (DAPI), mounted with Vectashield (Vector Laboratories), and visualized and pictures taken by fluorescence microscopy.

\section{Western blot analysis}

Proteins were extracted from HSR-GBM1, 040622 and 040821 treated with ATO for 72 hours. The cells were lysed, sonicated until clear, and then centrifuged at $4^{\circ} \mathrm{C}$ and $15000 \mathrm{rpm}$ for $10 \mathrm{~min}$ to remove cell debris. Subsequently, protein separation was performed on a $4-12 \%$ SDS-polyacrylamide gel by electrophoresis, and then transferred onto PVDF membranes. Membranes were then probed with primary antibodies overnight.

\section{Cell cycle analyses}

Cells were plated in 6-well plates at a density of $1.5 \times$ $10^{5}-2.5 \times 10^{5}$ cells per well and treated with ATO ranging from $0 \mu \mathrm{M}$ to $5 \mu \mathrm{M}$ for 72 hours. Cells were then fixed with $70 \%$ ethanol for at least 12 hours and stained with Guava Cell Cycle Reagent (Millipore, Billerica, MA). Cell cycle analyses were performed using the Guava PCA machine.

\section{Clonogenic assays}

HSR-GBM1, 040622 and 040821 neurospheres were treated with concentrations of ATO ranging between $0 \mu \mathrm{M}$ and $5 \mu \mathrm{M}$ for 72 hours. Neurospheres were then mechanically dissociated into single cells. 20000 viable cells were counted and plated in fresh media containing methylcellulose in 6-well plates. No ATO was present during this growth phase of the clonogenic assay. Pictures of colonies were taken after 10-12 days. 2-3 wells were plated per cell line and 3-4 separate fields were 
taken per well. Measurements were taken of the widest diameter of each colony and its corresponding right angle diameter and the measurements averaged. The number of colonies that have an average diameter above $100 \mu \mathrm{M}$ were then counted for each field and graphed.

\section{Flow cytometric analyses}

For CD133 flow cytometric analyses, neurospheres were treated with $0 \mu \mathrm{M}-5 \mu \mathrm{M}$ ATO for 24 hours and then collected, dissociated, and stained for CD133. Flow cytometry was then performed as previously described [43]. In brief, a PE-conjugated CD133 antibody (Miltenyl Biotec, Auburn, CA), was incubated on ice with the dissociated neurosphere cells for 10 minutes, protected from light. Cells were then washed and resuspended in $500 \mu \mathrm{l}$ of DMEM/F12 without phenol red containing $1 \%$ BSA. Cells incubated with isotype control in parallel were used to set the gates. Cells with PE-readings above isotype control were considered CD133-positive.

\section{Quantitative real-time PCR analyses}

HSR-GBM1, 040622 and 040821 were collected after treatment with $0 \mu \mathrm{M}-5 \mu \mathrm{M}$ ATO for 24 hours. RNA was then extracted, reversed transcribed, and cDNA levels analyzed by quantitative real-time PCR analysis performed in triplicate with SYBR Green reagents (Bio-Rad, Hercules, CA). Standard curves were used to determine expression levels and all values were normalized to be ta-actin. Statistical comparisons are between multiple experiments each with triplicate technical replicates. Primer sequences were as follows: HES1 forward 5'-GTC AAG CAC CTC CGGAAC-3'; HES1 reverse $5^{\prime}$-CGT TCA TGC ACT CGC TGA-3'; HEY1 forward 5'-TCT GAG CTG AGA AGG CTG GT-3'; HEY1 reverse 5' -CGA AAT CCC AAACTC CGA TA-3'; PTCH1B forward 5'-GAC GCC GCC TTC GCT CTG-3'; PTCH1B reverse 5'-GCC CAC AAC CAA GAA CTT GCC-3'; N-Myc forward 5' -CGACCACAAGGCCCTCAGTA -3'; N-Myc reverse 5'-CAGCCTTGGTGTTGGAGGAG-3' [44]; GLI2 forward 5'-AATCGCACCCACTCCAAC-3'; GLI2 reverse 5'-TGGGGTCTGTGTATCTCTTGG-3'; Human actin- $\beta$ forward - 5' -CCCAGCACAATGAA GATCAA- $3^{\prime}$; and human actin- $\beta$ reverse: $5^{\prime}$-GATCCA CACGGAGTACTTG- ${ }^{\prime}$.

\section{Statistical analyses}

Statistical significance was evaluated using unpaired, two-tailed Student's t-test. P-values $<0.05$ were considered statistically significant. Unless otherwise noted, error bars represent standard error of the mean. All statistical tests were performed using the GraphPad Prism 5 software (GraphPad Software, La Jolla, CA).

\section{Results}

ATO inhibits growth and promotes apoptosis in glioblastoma neurospheres

We first examined the effects of ATO on the growth of three glioblastoma neurosphere lines using the MTS assay. In all three lines, we saw a dose dependent reduction in growth over five days (Figure 1a). These studies were performed in technical triplicates at least 4 separate times for each cell line with similar results, and a bar graph containing all data points for the multiple experiments is shown in the lower right panel of Figure 1a. Mean growth inhibition of between $33-86 \%$ was seen after treatment at the $2.5 \mu \mathrm{M}$ ATO levels, and statistically significant $65-92 \%$ inhibition of growth was achieved by $5 \mu \mathrm{M}$ ATO in all three neurosphere lines. To directly determine the effects of ATO on the proliferation of glioblastoma neurospheres, we assessed the number of BRDU positive tumor cells after 72 hours of treatment in the three lines. We identified statistically significant reductions in proliferation of up to $90 \%$ using $2.5 \mathrm{uM}$ ATO, and even more pronounced effects with $5 \mu \mathrm{M}$ ATO (Figure 1B). These data suggest that decreased proliferation accounts for much of the slower growth we observed.

Induction of apoptosis may also mediate some of the anti-tumor effects of ATO. Cleaved caspase 3 levels were increased after ATO treatment in all three lines tested (Figure 2A). In addition, flow cytometric analysis revealed an increase in the sub-G1 fraction of all three lines which was significant at higher levels of the compound (Figure 2B). We also measured GFAP mRNA levels by quantitative RT PCR, but did not detect any increases suggesting increased glial differentiation of tumor cells (data not shown).

\section{ATO inhibits notch and hedgehog pathway targets}

Because ATO has been reported to suppress Hedgehog and Notch activity in other tumor types, we examined effects on the two pathways after 24 hour treatment of GBM neurosphere lines. Pathway activity was assessed using quantitative RT PCR to measure levels of the canonical pathway transcriptional targets PTCH1b, GLI2 and N-Myc (Hedgehog) as well as HES1, HES5 and HEY1 (Notch). At least two experimental replicates were performed, each with triplicate technical measurements, and all data points are combined in Figure 3. A statistically significant $40-89 \%$ inhibition of PTCH1b was noted at the highest ATO dose in all three lines, while the lesser $2.5 \mu \mathrm{M}$ dose resulted in significant inhibition in two of the three lines (Figure 3A). $2.5 \mu \mathrm{M}$ ATO also resulted in significant inhibition of another Hedgehog target, N-Myc, in all three GBM lines, while the highest ATO dose resulted in significant inhibition of two of the three lines (Figure 3A). $1 \mu \mathrm{M}$ ATO resulted in significant 

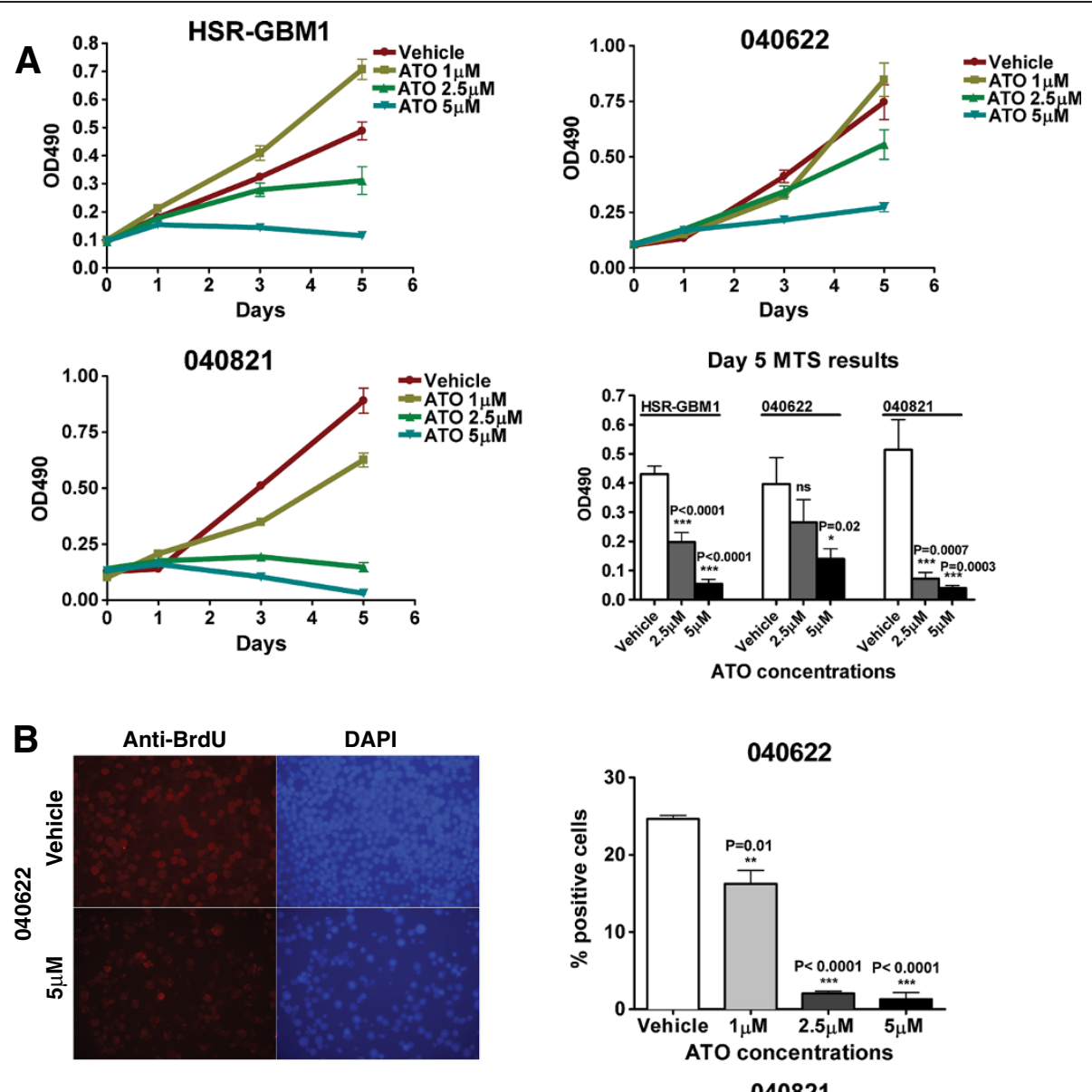

HSR-GBM1
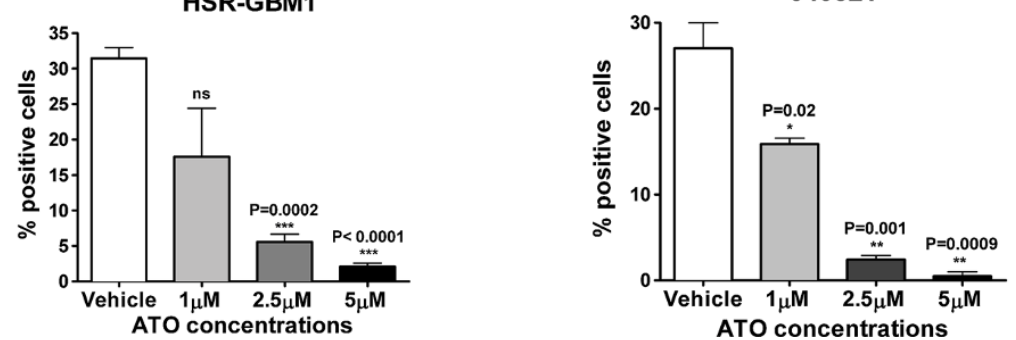

Figure 1 Arsenic trioxide inhibits glioblastoma neurosphere growth and proliferation. A) MTS assays showing growth inhibition following ATO treatment in the 040821, HSR-GBM1 and 040622 glioblastoma neurosphere lines, with a bar graph highlighting the significance compared to vehicle. B) Representative BRDU staining images showing anti-BRDU staining (red) and DAPI counterstaining (blue) in vehicle and $5 \mu$ M ATO-treated 040622 neurosphere cells are shown in the top left panel. The percentage of BRDU positive cells in 040622, 040821 and HSR-GBM1 neurospheres was significantly decreased in all three lines after treatment with either $2.5 \mu \mathrm{M}$ or $5 \mu \mathrm{M}$ ATO.

inhibition of a third downstream Hedgehog pathway member, GLI2, in HSR-GBM1 and 040622, while $2.5 \mu \mathrm{M}$ ATO resulted in significant inhibition in GBM1 and $5 \mu \mathrm{M}$ resulted in significant inhibition in all three GBM lines.

We also observed inhibition of Notch target expression in GBM neurospheres treated with ATO. These changes were not dose dependent in all the lines, but the $2.5 \mu \mathrm{M}$ level of ATO significantly suppressed HES5 and HEY1 in all three cultures, while the suppression of HES1 was significant in two of three (Figure 3B). Interestingly, the highest levels of ATO $(5 \mu \mathrm{M})$ resulted in an increase in the mRNA levels of HES5 and HEY1 in several lines. While the cause of this is not clear, we have previously observed paradoxical increases in the mRNA levels of Notch targets when treating brain tumor cells with high levels of gamma-secretase inhibitors that target Notch, and this may represent a feedback or resistance mechanism of some sort in cells surviving maximal therapy (CGE, unpublished data). In addition, ATO also resulted in a 


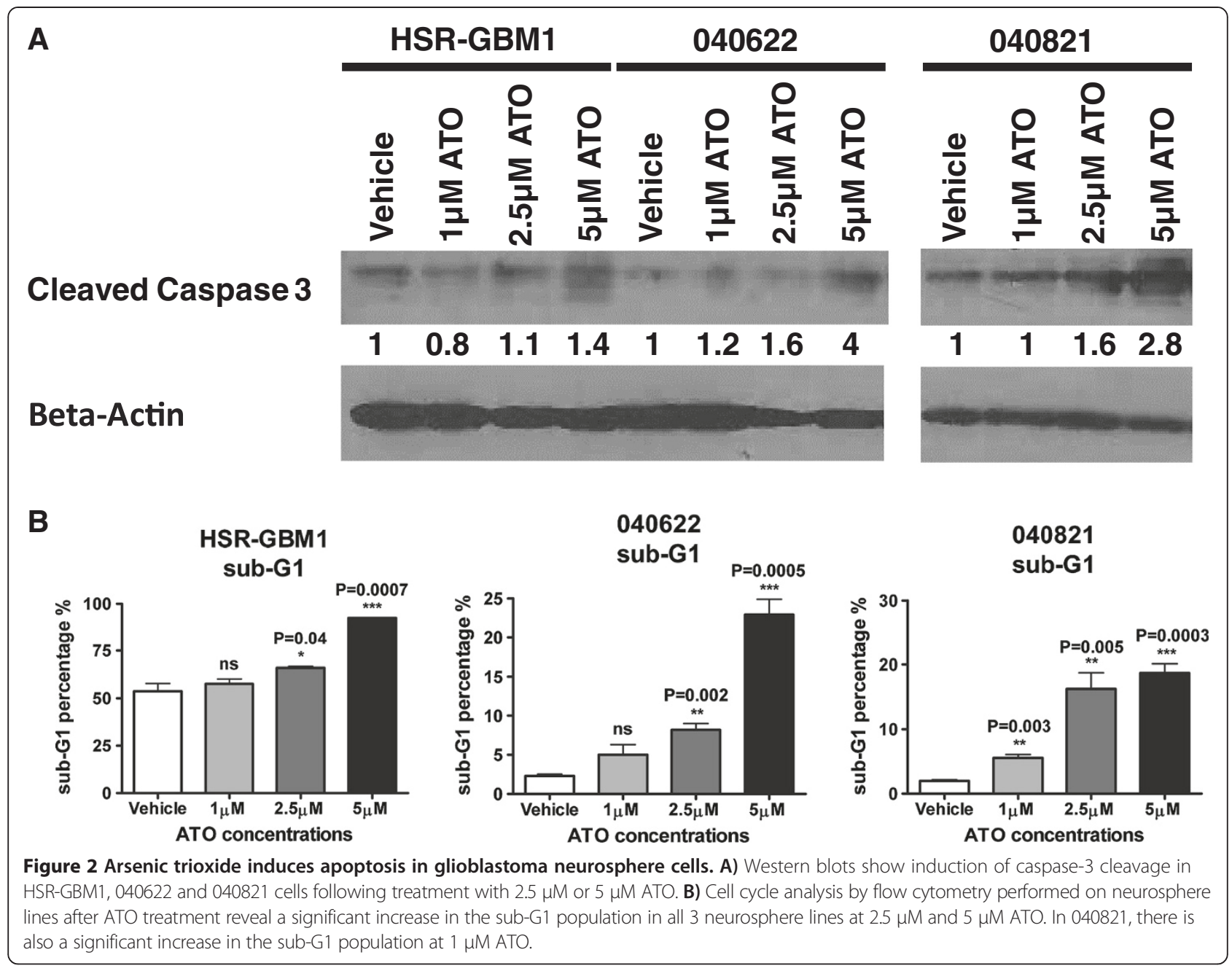

dose-dependent decrease of HES1 and HES5 at the protein level, further confirming the effect of ATO on Notch signaling (Figure 3C).

\section{Clonogenic capacity and stem cell markers are reduced following ATO treatment}

We next evaluated the effects of ATO treatment on the clonogenic capacity of glioblastoma cells. Neurosphere lines were treated for three days with ATO, triturated, and counted. Equal numbers of surviving cells were then seeded into methylcellulose and allowed to grow into colonies with no additional treatment. We have previously shown that only large glioblastoma spheres grown in methylcellulose can be serially passaged [45]. The number of spheres over $100 \mu \mathrm{M}$ in size was significantly reduced following ATO treatment in HSR-GBM1 and 040821 cells (Figure 4), while a modest non-significant reduction was seen in 040622 cells (data not shown). This suggested that the stem-like clonogenic fraction is depleted by ATO treatment.
To more directly examine the effects of ATO on stem cell markers, we measured levels of SOX2 and CD133 mRNA after 24 hours of treatment. For the HSR-GBM1 and 040622 lines, a dose-dependent significant inhibition in CD133 mRNA expression was seen (Figure 5A, B). Reductions in SOX2 mRNA levels were also noted in all three lines, and were significant in 040622 (Figure 5B).

We also used flow cytometric analysis to measure the fraction of cells expressing the marker CD133 on their surface. Triplicate analyses showed significant reductions in this stem-like cell fraction at both $2.5 \mu \mathrm{M}$ and $5 \mu \mathrm{M}$ levels of ATO in all three lines (Figure 5C). The changes were most pronounced in the HSR-GBM1 and 040821 lines, and relatively modest in the 040622 cells. This experiment was repeated twice with similar results.

\section{Discussion}

Standard GBM treatment includes surgical resection followed by radiotherapy and temozolomide (TMZ) chemotherapy, but rarely results in long term survival [46]. In this study, we focused on the potential of ATO 


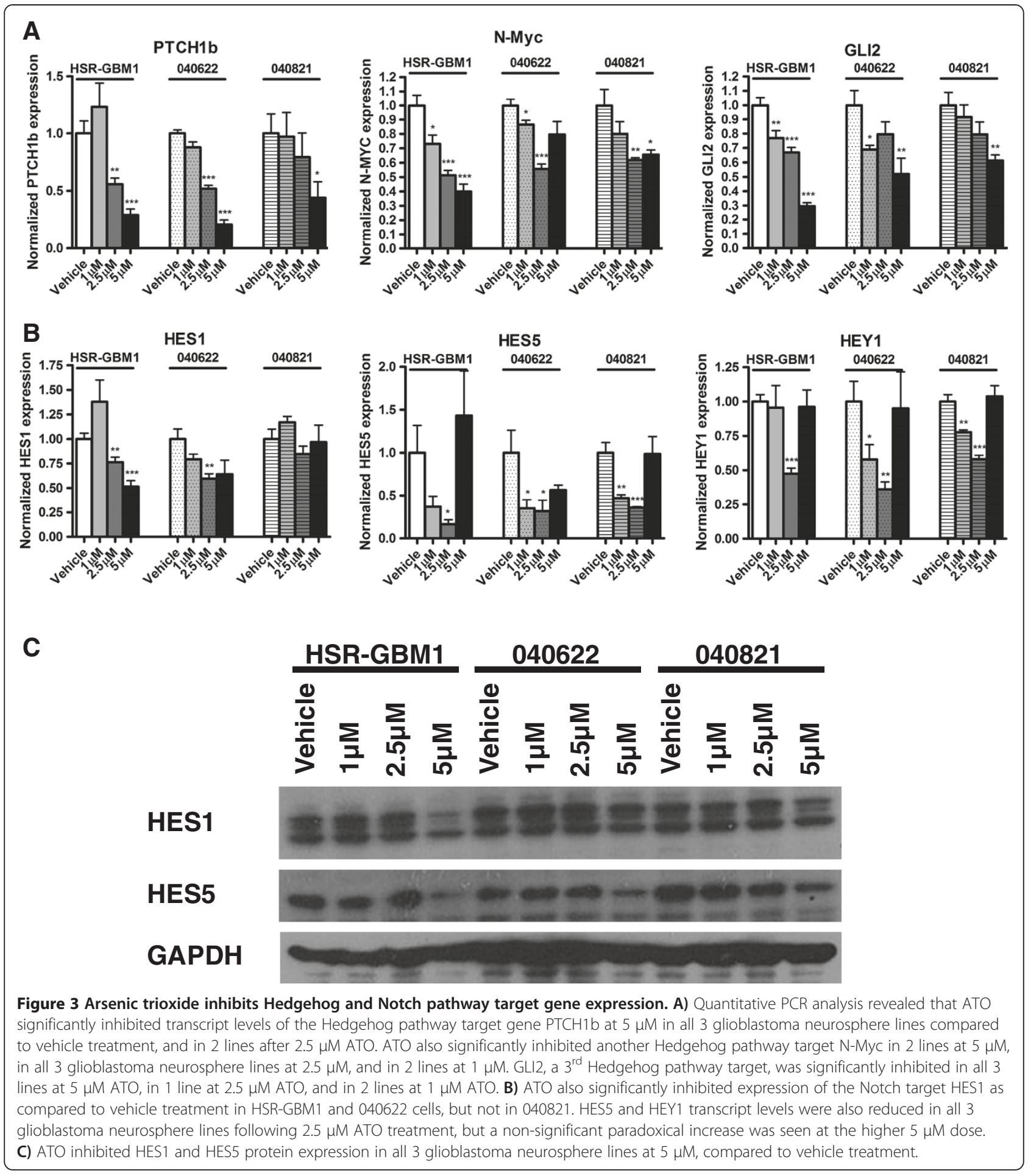

as a therapeutic agent for GBM patients, particularly its ability to inhibit the Notch and Hedgehog pathways which have been shown to play key roles in stem-like glioma cells. While both of these pathways have been shown to be inhibited by ATO in some tumor types $[47,48]$, the ability of this compound to affect them in gliomas is less clear.
Zhen and colleagues treated three adherent GBM lines (U87MG, U251MG and U373MG) with ATO and reported decreased protein levels of the Notch1 receptor and HES1 target, as well as reductions in growth in vitro and in vivo [30]. They also identified lower levels of the stem/progenitor marker Nestin after treatment, although as noted above high serum lines are not thought to be 
A

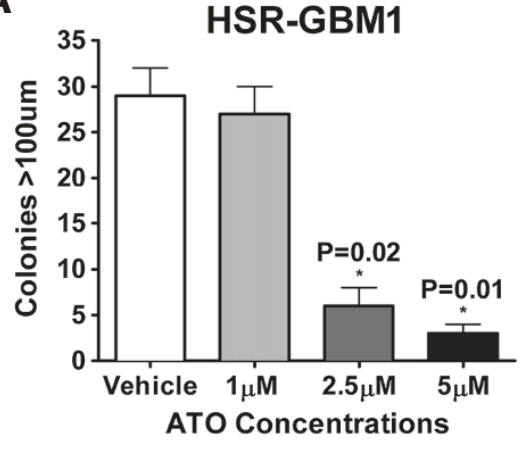

B

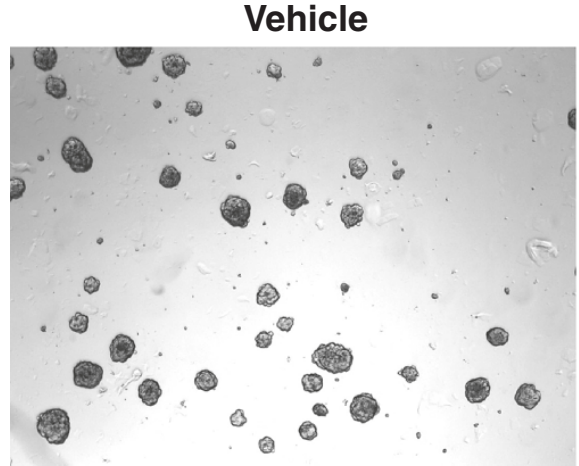

HSR-GBM1

$5 \mu \mathrm{M}$

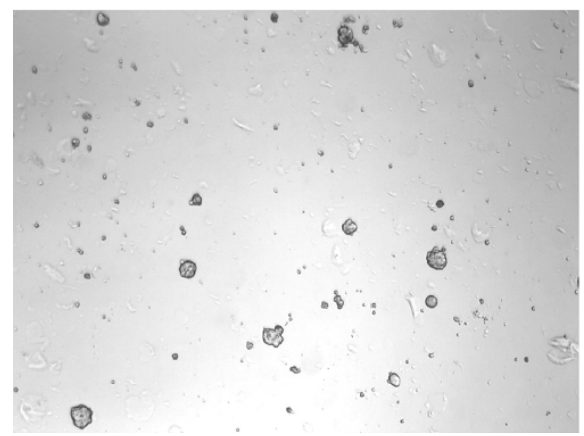

040821

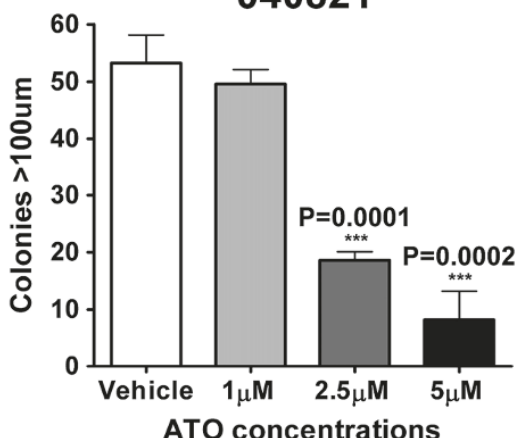

040821

Vehicle
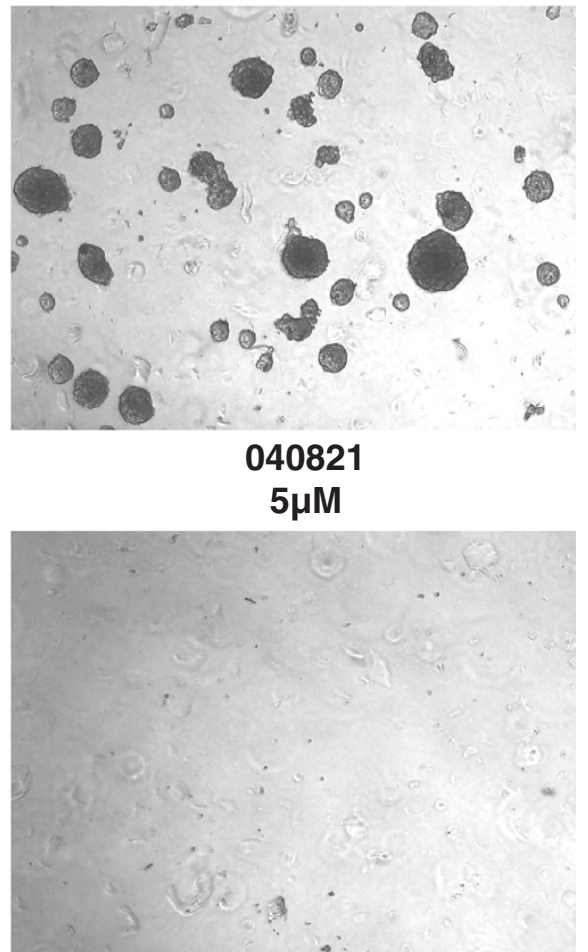

Figure 4 Arsenic trioxide treatment inhibits clonogenicity in glioblastoma neurosphere cells. A) Quantification of clonogenicity in equal numbers of single viable HSR-GBM1 and 040821 cells seeded in methylcellulose following 3 days of ATO treatment showed significantly fewer colonies over $100 \mu \mathrm{M}$ in size. B) Representative images of colonies.

good models of cancer stem cells in glioma. To our knowledge, no data addressing the effects of ATO on Hedgehog activity in glioma has been published.

We examined the effects of ATO inhibition on Notch and Hedgehog pathways in three GBM neurosphere lines which we have previously shown to contain stem-like fractions that require one or both of these signaling cascades $[7,8,18]$. We found that ATO inhibits growth and clonogenicity with induction of apoptosis in all three lines. CD133 percentage, as assessed by flow and quantitative real-time PCR, as well as the levels of other stem cell transcripts, were also reduced following ATO treatment. Finally, we found significant reductions in the expression of both Notch and Hedgehog pathway targets.

A recently published study by $\mathrm{Wu}$ et al. [47] also examined the effects of ATO on Notch signaling and clonogenic growth in several adherent GBM lines as well as what appeared to be a single neurosphere culture [47]. Like us, they found reductions in stem cell markers and phenotype in the glioma cells following ATO treatment, which they suggest were at least partially due to effects on Notch. They did not examine Hedgehog pathway 


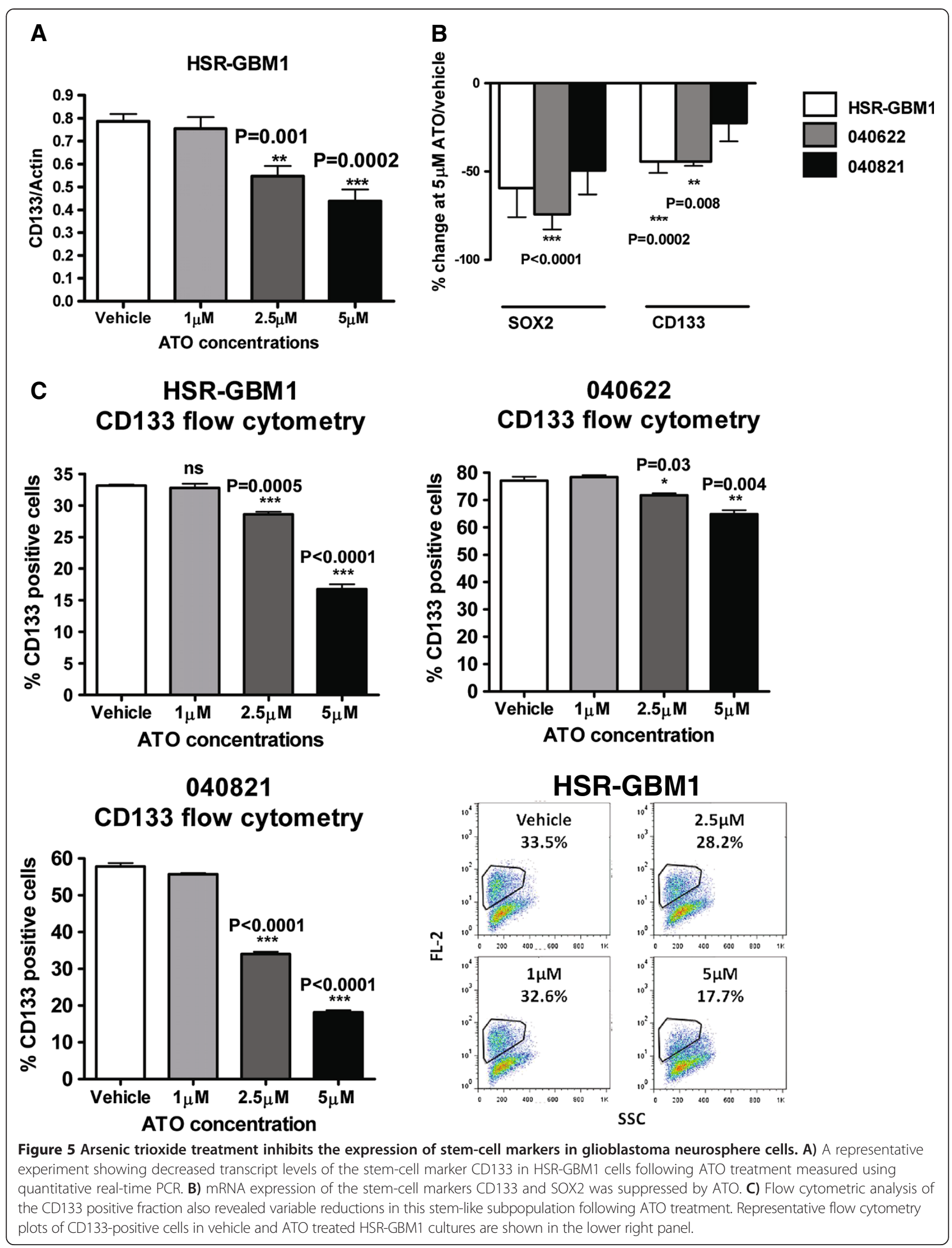


inhibition. In two studies of ATO treatment in leukemia patients, cerebrospinal fluid levels were $10-17 \%$ of those in serum, thus local delivery may be necessary in brain tumor patients $[49,50]$.

In summary, ATO has been previously shown to inhibit the growth of high serum GBM cultures, but little was known about its effects on glioma stem cells or the pathways thought to promote their specification and survival. We found that ATO depletes stem-like cancer cells as defined by surface CD133 expression in all three GBM neurosphere lines tested, with negative effects on overall growth and clonogenicity. We also noted inhibition of both Notch and Hedgehog signaling by ATO, suggesting a potential mechanism for the effects on cancer stem cells and tumor growth. Our findings are consistent with another recent study of ATO and Notch signaling in GBM neurospheres, and together these and prior reports support the development of ATO as a clinical therapeutic agent capable of inhibiting multiple signaling pathways important in stem like glioma cells.

\section{Competing interests}

The authors declare that they have no competing interests.

\section{Authors' contributions}

DD and KSL performed cell culture and molecular studies, collected and interpreted data, and helped to draft the manuscript. CGE helped with experimental design, interpretation of data and drafted the manuscript. All authors read and approved the final manuscript.

\section{Acknowledgements}

We would like to thank Antionette Price and the rest of the Eberhart lab for technical assistance and scientific discussions. This work was supported by RO1NS055089 (CGE).

\section{Author details}

'Department of Neurosurgery, Xiangya Hospital of Central South University, 87 Xiangya Road, Changsha, Hunan 410078, China. ${ }^{2}$ Departments of Pathology, Johns Hopkins University School of Medicine, Baltimore, MD 21287, USA. ${ }^{3}$ Oncology, Johns Hopkins University School of Medicine, Baltimore, MD 21287, USA. ${ }^{4}$ Ophthalmology, Johns Hopkins University School of Medicine, Baltimore, MD 21287, USA.

Received: 24 January 2014 Accepted: 15 March 2014

Published: 31 March 2014

\section{References}

1. Eyler $C E$, Rich JN: Survival of the fittest: cancer stem cells in therapeutic resistance and angiogenesis. J Clin Oncol 2008, 26:2839-2845.

2. O'Brien CA, Kreso A, Dick JE: Cancer stem cells in solid tumors: an overview. Semin Radiat Oncol 2009, 19:71-77.

3. Reya T, Morrison SJ, Clarke MF, Weissman IL: Stem cells, cancer, and cancer stem cells. Nature 2001, 414:105-111.

4. Dean M, Fojo T, Bates S: Tumour stem cells and drug resistance. Nat Rev Cancer 2005, 5:275-284.

5. Wicha MS, Liu S, Dontu G: Cancer stem cells: an old idea-a paradigm shift. Cancer Res 2006, 66:1883-1890. discussion 1895-1886.

6. Visvader JE, Lindeman GJ: Cancer stem cells in solid tumours: accumulating evidence and unresolved questions. Nat Rev Cancer 2008, 8:755-768.

7. Fan X, Khaki L, Zhu TS, Soules ME, Talsma CE, Gul N, Koh C, Zhang J, Li YM, Maciaczyk J, Nikkhah G, Dimeco F, Piccirillo S, Vescovi AL, Eberhart CG: NOTCH pathway blockade depletes CD133-positive glioblastoma cells and inhibits growth of tumor neurospheres and xenografts. Stem cells 2010, 28:5-16.
8. Bar EE, Chaudhry A, Lin A, Fan X, Schreck K, Matsui W, Piccirillo S, Vescovi AL, DiMeco F, Olivi A, Eberhart CG: Cyclopamine-mediated hedgehog pathway inhibition depletes stem-like cancer cells in glioblastoma. Stem Cells 2007, 25:2524-2533.

9. Clement V, Sanchez P, de Tribolet N, Radovanovic I, Altaba R i: HEDGEHOG-GLI1 signaling regulates human glioma growth, cancer stem cell self-renewal, and tumorigenicity. Curr Biol 2007, 17:165-172.

10. Ehtesham M, Sarangi A, Valadez JG, Chanthaphaychith S, Becher MW, Abel TW, Thompson RC, Cooper MK: Ligand-dependent activation of the hedgehog pathway in glioma progenitor cells. Oncogene 2007, 26:5752-5761.

11. Sarangi A, Valadez JG, Rush S, Abel TW, Thompson RC, Cooper MK: Targeted inhibition of the hedgehog pathway in established malignant glioma xenografts enhances survival. Oncogene 2009, 28:3468-3476.

12. Purow BW, Haque RM, Noel MW, Su Q, Burdick MJ, Lee J, Sundaresan T, Pastorino S, Park JK, Mikolaenko I, Maric D, Eberhart CG, Fine HA: Expression of Notch-1 and its ligands, Delta-like-1 and Jagged-1, is critical for glioma cell survival and proliferation. Cancer Res 2005, 65:2353-2363.

13. Shih AH, Holland EC: Notch signaling enhances nestin expression in gliomas. Neoplasia 2006, 8:1072-1082.

14. Zhang XP, Zheng G, Zou L, Liu HL, Hou LH, Zhou P, Yin DD, Zheng QJ, Liang L, Zhang SZ, Feng L, Yao LB, Yang AG, Han H, Chen JY: Notch activation promotes cell proliferation and the formation of neural stem cell-like colonies in human glioma cells. Mol Cell Biochem 2008, 307:101-108.

15. Kanamori M, Kawaguchi T, Nigro JM, Feuerstein BG, Berger MS, Miele L, Pieper RO: Contribution of notch signaling activation to human glioblastoma multiforme. J Neurosurg 2007, 106:417-427.

16. Wang J, Wakeman TP, Lathia JD, Hjelmeland AB, Wang XF, White RR, Rich $\mathrm{JN}$, Sullenger BA: Notch promotes radioresistance of glioma stem cells. Stem Cells 2010, 28:17-28.

17. Hu YY, Zheng MH, Cheng G, Li L, Liang L, Gao F, Wei YN, Fu LA, Han H: Notch signaling contributes to the maintenance of both normal neural stem cells and patient-derived glioma stem cells. BMC Cancer 2011, 11:82.

18. Schreck KC, Taylor P, Marchionni L, Gopalakrishnan V, Bar EE, Gaiano N, Eberhart CG: The Notch target Hes1 directly modulates Gli1 expression and Hedgehog signaling: a potential mechanism of therapeutic resistance. Clin Cancer Res 2010, 16:6060-6070.

19. Shen ZX, Chen GQ, Ni JH, Li XS, Xiong SM, Qiu QY, Zhu J, Tang W, Sun GL, Yang KQ, Chen Y, Zhou L, Fang ZW, Wang YT, Ma J, Zhang P, Zhang TD, Chen SJ, Chen Z, Wang ZY: Use of arsenic trioxide (As2O3) in the treatment of acute promyelocytic leukemia (APL): Il. Clinical efficacy and pharmacokinetics in relapsed patients. Blood 1997, 89:3354-3360.

20. Chen GQ, Zhu J, Shi XG, Ni JH, Zhong HJ, Si GY, Jin XL, Tang W, Li XS, Xong SM, Shen ZX, Sun GL, Ma J, Zhang P, Zhang TD, Gazin C, Naoe T, Chen SJ, Wang ZY, Chen Z: In vitro studies on cellular and molecular mechanisms of arsenic trioxide (As2O3) in the treatment of acute promyelocytic leukemia: As2O3 induces NB4 cell apoptosis with downregulation of BCl-2 expression and modulation of PML-RAR alpha/PML proteins. Blood 1996, 88:1052-1061.

21. Cohen MH, Hirschfeld S, Flamm Honig S, Ibrahim A, Johnson JR, O'Leary JJ, White RM, Williams GA, Pazdur R: Drug approval summaries: arsenic trioxide, tamoxifen citrate, anastrazole, paclitaxel, bexarotene. Oncologist 2001, 6:4-11.

22. Maeda H, Hori S, Nishitoh H, Ichijo H, Ogawa O, Kakehi Y, Kakizuka A: Tumor growth inhibition by arsenic trioxide (As2O3) in the orthotopic metastasis model of androgen-independent prostate cancer. Cancer Res 2001, 61:5432-5440.

23. Shen ZY, Shen J, Cai WJ, Hong C, Zheng MH: The alteration of mitochondria is an early event of arsenic trioxide induced apoptosis in esophageal carcinoma cells. Int J Mol Med 2000, 5:155-158.

24. Akao Y, Nakagawa Y, Akiyama K: Arsenic trioxide induces apoptosis in neuroblastoma cell lines through the activation of caspase 3 in vitro. FEBS Lett 1999, 455:59-62.

25. Park WH, Seol JG, Kim ES, Hyun JM, Jung CW, Lee CC, Kim BK, Lee YY: Arsenic trioxide-mediated growth inhibition in MC/CAR myeloma cells via cell cycle arrest in association with induction of cyclin-dependent kinase inhibitor, p21, and apoptosis. Cancer Res 2000, 60:3065-3071.

26. Rousselot P, Labaume S, Marolleau JP, Larghero J, Noguera MH, Brouet JC, Fermand JP: Arsenic trioxide and melarsoprol induce apoptosis in plasma cell lines and in plasma cells from myeloma patients. Cancer Res 1999, 59:1041-1048. 
27. Kanzawa T, Kondo Y, Ito H, Kondo S, Germano I: Induction of autophagic cell death in malignant glioma cells by arsenic trioxide. Cancer Res 2003 63:2103-2108

28. Nasr R, Guillemin MC, Ferhi $O$, Soilihi $H$, Peres L, Berthier C, Rousselot $P$, Robledo-Sarmiento M, Lallemand-Breitenbach V, Gourmel B, Vitoux D, Pandolfi PP, Rochette-Egly C, Zhu J, de Thé H: Eradication of acute promyelocytic leukemia-initiating cells through PML-RARA degradation. Nat Med 2008, 14:1333-1342.

29. Kim J, Aftab BT, Tang JY, Kim D, Lee AH, Rezaee M, Kim J, Chen B, King EM, Borodovsky A, Riggins GJ, Epstein EH Jr, Beachy PA, Rudin CM: Itraconazole and arsenic trioxide inhibit Hedgehog pathway activation and tumor growth associated with acquired resistance to smoothened antagonists. Cancer Cell 2013, 23:23-34.

30. Zhen Y, Zhao S, Li Q, Li Y, Kawamoto K: Arsenic trioxide-mediated Notch pathway inhibition depletes the cancer stem-like cell population in gliomas. Cancer Lett 2010, 292:64-72.

31. Ning S, Knox SJ: Increased cure rate of glioblastoma using concurrent therapy with radiotherapy and arsenic trioxide. Int J Radiat Oncol Biol Phys 2004, 60:197-203.

32. Chiu HW, Ho SY, Guo HR, Wang YJ: Combination treatment with arsenic trioxide and irradiation enhances autophagic effects in U118-MG cells through increased mitotic arrest and regulation of PI3K/Akt and ERK1/2 signaling pathways. Autophagy 2009, 5:472-483.

33. Kim JH, Lew YS, Kolozsvary A, Ryu S, Brown SL: Arsenic trioxide enhances radiation response of $9 \mathrm{~L}$ glioma in the rat brain. Radiat Res 2003, 160:662-666.

34. Wei Y, Liu D, Ge Y, Zhou F, Xu J, Chen H, Yun X, Gu J, Jiang J: Down-regulation of beta1,4GalT $V$ at protein level contributes to arsenic trioxide-induced glioma cell apoptosis. Cancer Lett 2008, 267:96-105.

35. Song X, Chen Z, Wu C, Zhao S: Abrogating HSP response augments cell death induced by As2O3 in glioma cell lines. Can J Neurol Sci 2010, 37:504-511.

36. Sun $H$, Zhang S: Arsenic trioxide regulates the apoptosis of glioma cell and glioma stem cell via down-regulation of stem cell marker Sox2. Biochem Biophys Res Commun 2011, 410:692-697.

37. Pucer A, Castino R, Mirkovic B, Falnoga I, Slejkovec Z, Isidoro C, Lah T: Differential role of cathepsins $B$ and $L$ in autophagy-associated cell death induced by arsenic trioxide in U87 human glioblastoma cells. Biol Chem 2010, 391:519-531.

38. Chiu HW, Ho YS, Wang YJ: Arsenic trioxide induces autophagy and apoptosis in human glioma cells in vitro and in vivo through downregulation of survivin. J Mol Med 2011, 89:927-941.

39. Haga N, Fujita N, Tsuruo T: Involvement of mitochondrial aggregation in arsenic trioxide (As2O3)-induced apoptosis in human glioblastoma cells. Cancer Sci 2005, 96:825-833.

40. Kanzawa T, Zhang L, Xiao L, Germano IM, Kondo Y, Kondo S: Arsenic trioxide induces autophagic cell death in malignant glioma cells by upregulation of mitochondrial cell death protein BNIP3. Oncogene 2005, 24:980-991.

41. Lee J, Kotliarova S, Kotliarov Y, Li A, Su Q, Donin NM, Pastorino S, Purow BW Christopher N, Zhang W, Park JK, Fine HA: Tumor stem cells derived from glioblastomas cultured in bFGF and EGF more closely mirror the phenotype and genotype of primary tumors than do serum-cultured cell lines. Cancer Cell 2006, 9:391-403.

42. Chu Q, Orr BA, Semenkow S, Bar EE, Eberhart CG: Prolonged inhibition of glioblastoma xenograft initiation and clonogenic growth following in vivo Notch blockade. Clin Cancer Res 2013, 19:3224-3233.

43. Fan X, Matsui W, Khaki L, Stearns D, Chun J, Li YM, Eberhart CG: Notch pathway inhibition depletes stem-like cells and blocks engraftment in embryonal brain tumors. Cancer Res 2006, 66:7445-7452.

44. Bordow SB, Haber M, Madafiglio J, Cheung B, Marshall GM, Norris MD: Expression of the multidrug resistance-associated protein (MRP) gene correlates with amplification and overexpression of the N-myc oncogene in childhood neuroblastoma. Cancer Res 1994, 54:5036-5040.

45. Bar EE, Lin A, Mahairaki V, Matsui W, Eberhart CG: Hypoxia increases the expression of stem-cell markers and promotes clonogenicity in glioblastoma neurospheres. Am J Pathol 2010, 177:1491-1502.

46. Clarke J, Penas C, Pastori C, Komotar RJ, Bregy A, Shah AH, Wahlestedt C, Ayad NG: Epigenetic pathways and glioblastoma treatment. Epigenetics 2013, 8:785-795.

47. Wu J, Ji Z, Liu H, Liu Y, Han D, Shi C, Shi C, Wang C, Yang G, Chen X, Shen C, Li H, Bi Y, Zhang D, Zhao S: Arsenic trioxide depletes cancer stem-like cells and inhibits repopulation of neurosphere derived from glioblastoma by downregulation of Notch pathway. Toxicol Lett 2013, 220:61-69.

48. Yang D, Cao F, Ye X, Zhao H, Liu X, Li Y, Shi C, Wang H, Zhou J: Arsenic trioxide inhibits the Hedgehog pathway which is aberrantly activated in acute promyelocytic leukemia. Acta Haematol 2013, 130:260-267.

49. Au WY, Tam S, Fong BM, Kwong YL: Determinants of cerebrospinal fluid arsenic concentration in patients with acute promyelocytic leukemia on oral arsenic trioxide therapy. Blood 2008, 112:3587-3590.

50. Kiguchi T, Yoshino Y, Yuan B, Yoshizawa S, Kitahara T, Akahane D, Gotoh M, Kaise T, Toyoda H, Ohyashiki K: Speciation of arsenic trioxide penetrates into cerebrospinal fluid in patients with acute promyelocytic leukemia. Leuk Res 2010, 34:403-405.

doi:10.1186/2051-5960-2-31

Cite this article as: Ding et al:: Arsenic trioxide inhibits Hedgehog, Notch and stem cell properties in glioblastoma neurospheres. Acta

Neuropathologica Communications 2014 2:31

\section{Submit your next manuscript to BioMed Central and take full advantage of:}

- Convenient online submission

- Thorough peer review

- No space constraints or color figure charges

- Immediate publication on acceptance

- Inclusion in PubMed, CAS, Scopus and Google Scholar

- Research which is freely available for redistribution 